\title{
Feasibility of second-generation bioresorbable vascular scaffold implantation in complex anatomical and clinical scenarios
}

\author{
Milosz Jaguszewski • Jelena-Rima Ghadri • Manuel Zipponi · Dana Roxana Bataiosu • \\ Johanna Diekmann • Verena Geyer - Catharina Anna Neumann - Mia Aurelia Huber • \\ Christian Hagl • Paul Erne · Thomas F. Lüscher · Christian Templin
}

Received: 26 June 2014/Accepted: 11 August 2014/Published online: 31 August 2014

(C) The Author(s) 2014. This article is published with open access at Springerlink.com

\begin{abstract}
Background Bioresorbable vascular scaffolds (BVS) have become an emerging tool to treat coronary artery disease. However, the current use of BVS is still widely restricted to stable patients and non-complex lesions. In real-world practice patients are far more complex than those with simple type A lesions and the extended use of BVS to complex lesions and high-risk patients needs to be evaluated. Therefore, we sought to investigate the feasibility and performance of BVS in a broad spectrum of patients.

Methods 106 patients underwent in total 193 BVS implantations. We assessed the device-related (cardiac death, target vessel myocardial infarction, ischemia-driven target lesion revascularization) and patient-related (all-
\end{abstract}

Electronic supplementary material The online version of this article (doi:10.1007/s00392-014-0757-4) contains supplementary material, which is available to authorized users.

M. Jaguszewski · J.-R. Ghadri · M. Zipponi ·

D. R. Bataiosu · J. Diekmann · V. Geyer .

C. A. Neumann · T. F. Lüscher · C. Templin ( $\square)$

University Heart Center, University Hospital Zurich, Raemistr.

100, 8091 Zurich, Switzerland

e-mail: Christian.Templin@usz.ch

M. A. Huber

Faculty of Law, University of Zurich, Zurich, Switzerland

C. Hagl

Department of Heart and Thoracic Surgery,

Ludwig-Maximilians University Munich, Munich, Germany

P. Erne

Department of Cardiology, Kantonal Hospital of Lucerne,

Lucerne, Switzerland cause death, any reinfarction and any revascularization) composite outcomes.

Results $90 \%$ of patients $(n=95)$ had at least one of the following characteristics: $>65$ years $(35 \%)$, ACS (42\%), tortuous vessels $(13 \%)$, calcified $(17 \%)$ or thrombotic lesions (12\%), lesions defined as AHA type B2/C (42\%), bifurcations $(16 \%)$, chronic total occlusions $(9 \%)$ or restenosis $(14 \%)$. There was no evidence of significant edge dissection, huge thrombus load or incidence of scaffold dislodgement or scaffold disruption in optical coherence tomography pullbacks. Out of 10,157 struts evaluated within 1,117 cross-sections, 302 were classified as malapposed $(2.9 \%)$. During a mean follow-up of $147 \pm 119$ days the rate of device-related events was $2.0 \%$, whereas patient-related composite events occurred in $6.1 \%$.

Conclusions Our results strongly suggest that BVS implantation is feasible in a wide spectrum of patients and complex anatomy of coronary lesions. Long-term outcome of BVS should be further investigated in unrestricted settings in randomized controlled trials.

Keywords Bioresorbable vascular scaffold · Optical coherence tomography

\section{Introduction}

The first plain-old balloon angioplasty (POBA) performed by Andreas Gruentzig in 1977 in Zurich, Switzerland, revolutionized the treatment strategy of coronary artery disease (CAD) [1]. The common acute and chronic recoil was reduced by the subsequent introduction of bare-metal stents (BMS), as reported in the BENESTENT trial [2]. However, as the restenosis rate remained high with BMS, 
drug-eluting stents (DES) were developed. Although the first-generation DES essentially reduced the need for urgent revascularization as compared to BMS, their propensity for late stent thrombosis (ST) was a concern [3]. Furthermore, the need for target lesion revascularization after DES implantation remains a still not fully resolved issue. The design of new second-generation DES with biocompatible polymer coatings allowed for improved deliverability, endothelial healing and therefore better device-rated outcomes [4]. Nowadays, the new technology of bioresorbable vascular scaffolds (BVS) remains a ray of hope in the field of interventional cardiology. Nonetheless, data are still lacking regarding their use in a real-world setting. Indeed, so far these novel scaffolds have been exclusively used in stable patients with noncomplex lesions [5-8]. Currently, only little data exist regarding real-world use of these devices, i.e., in patients with acute coronary syndromes (ACS), chronic total occlusions (CTO), bifurcations, and restenosis [9-13]. We therefore aimed to investigate the clinical outcome after BVS implantation in two highly experienced centers in a wide patient spectrum.

\section{Methods}

Population, data collection, and procedures

The study flowchart is presented in Fig. 1. Patients from two Swiss tertiary cardiology centers (University Heart Center, Cardiology, Zurich and Cardiology, Regional Hospital Lucerne) with stable CAD or ACS who qualified for percutaneous coronary intervention (PCI) were enrolled from September 2012 to December 2013. Eligible patients had at least one coronary artery lesion and no restrictions as

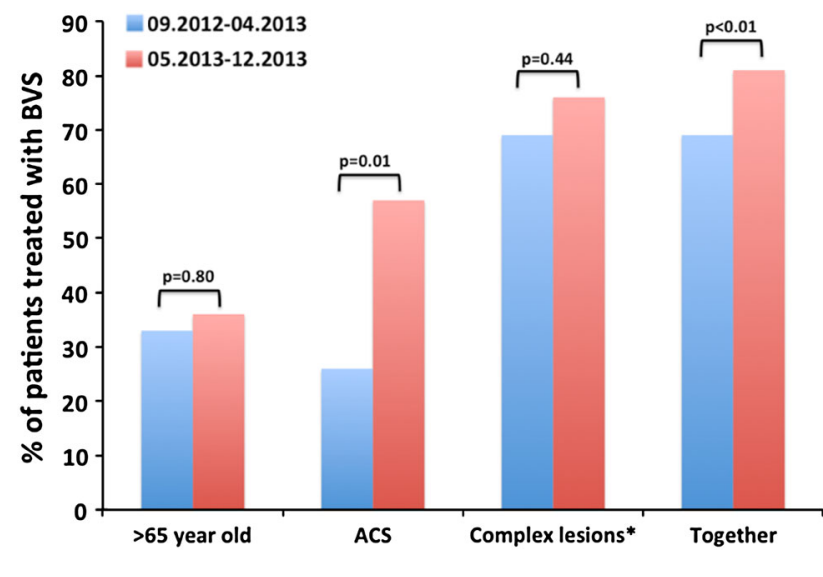

*B2/C lesions, CTO, bifurcations, massive calcifications, restenosis, thrombus, tortuosity

Fig. 1 Temporal trends in patients' age and lesion characteristic for the usage of BVS to the number, severity and location of stenosis. All patients were implanted with at least one second-generation BVS (Abbott Vascular, Santa Clara, California) designed with semicrystalline poly-L-lactide (PLLA) and coated with an amorphous poly-D, L-lactide (PDLA) polymer eluting everolimus. The reason for the selection of BVS was left to the discretion of the operator. Medical records including demographics, clinical, angiographic and procedural features were collected with the use of special electronic databases. The use of anonymized data, originating from retrospective analysis of personal data from own patients exclusively, requires no approval by the local ethics committee.

The intervention was obtained according to the current PCI guidelines. All lesions were prepared with the use of balloon dilatation before each BVS implantation and BVS deployment was performed in line with the manufacturer's recommendations at a rate of 2 atmospheres per $5 \mathrm{~s}$ up to rated burst pressure. If more than one BVS was implanted, the overlap technique or adjacent-positioning technique was used.

Coronary angiography was performed in the left coronary system with two radiation exposures in four projections and in the right coronary artery with two exposures in two projections. Lesions were classified according to the AHA/ACC criteria as follows-type A: minimally complex, concentric, readily accessible of length $<10 \mathrm{~mm}$ in non-angulated segment $\left(<45^{\circ}\right)$, with little or no calcification, less than totally occlusive, not ostial in location, with no major side branch (SB) involvement, and no apparent thrombus; type B1: moderately complex, with a length of $10-20 \mathrm{~mm}$, eccentric and with irregular contour, moderate or heavy calcification in a proximal segment of moderate tortuosity, moderately angulated $\left(>45\right.$ and $\left.<90^{\circ}\right)$, total occlusions $<3$ months old, ostial in location, and bifurcation lesions requiring double guidewires with some thrombus present; type B2: lesions demonstrating two or more type B1 characteristics; type C: severely complex, with length of $>20 \mathrm{~mm}$, in a tortuous, proximal, extremely angulated segment, total occlusions $>3$ months old and/or bridging collaterals, and degenerated vein grafts.

Patients were treated with dual antiplatelet therapy (DAPT) comprising a loading dose of aspirin $500 \mathrm{mg}$ i.v., followed by the maintained daily dose of $100 \mathrm{mg}$, and clopidogrel $600 \mathrm{mg}$ p.o. followed by the maintained daily dose of $75 \mathrm{mg}$ for 12 months or prasugrel $60 \mathrm{mg}$ p.o. continued with $10 \mathrm{mg}$ daily dose or ticagrelor $180 \mathrm{mg}$ loading dose and continued with $2 \times 90 \mathrm{mg}$ daily dose. Heparin was administered intravenously to maintain the activated clotting time of at least $250 \mathrm{~s}$. The use of thrombectomy and GP IIb/IIIa administration was at the discretion of the respective cardiologist. Manual 
thrombectomy was performed using an Export catheter (Medtronic Inc., Minneapolis, USA).

\section{Definitions}

ST-segment elevation myocardial infarction (STEMI) was defined as a new ST-segment elevation of at least $1 \mathrm{~mm}$ in two or more contiguous leads or new left bundle branch block (LBBB) concomitant with elevated troponin level [14]. Non-ST-segment elevation myocardial infarction (NSTEMI) was defined as the elevation of biomarkers of myocardial necrosis (e.g., troponin) with no evidence of ST-segment elevation in the ECG in the presence of angina chest pain [15]. CTO was defined as a complete obstruction of coronary artery with thrombolysis in myocardial infarction (TIMI) flow grade 0 and an estimated time of occlusion of at least 3 months [16]. Target lesion revascularization (TLR) was defined as repeat intervention in a de novo lesion within the stented segment with a luminal diameter of $\geq 50 \%$ or within a $5 \mathrm{~mm}$ border zone proximal or distal to the stent. An "off-label indication" was defined as a BVS implantation in patients $>65$ years, those referred for primary PCI due to an ACS, in tortuous vessels, calcified or thrombotic lesions, lesions defined as AHA type B2/C, bifurcation lesions, CTO, and in restenosis.

Optical coherence tomography (OCT)

The C7-XR OFDI system (LightLab Imaging, Inc, St Jude Medical, St. Paul, MN, USA) was optionally used to acquire images during intracoronary injection of contrast media with an optical fiber Dragonfly or Dragonfly Duo catheter. The Dragonfly catheter was positioned over a conventional $0.014^{\prime}$ angioplasty guidewire and automated pullback $(20 \mathrm{~mm} / \mathrm{s})$, with an image acquisition at 100 frames/s, and contrast injection $(6 \mathrm{~mL} / \mathrm{s})$ was used to acquire all images.

All pullbacks were analyzed post hoc in our core laboratory of the Andreas Gruentzig Catheterization Laboratories at the University Heart Center, University Hospital of Zurich, Switzerland using proprietary software (ILUMIEN OPTIS system, Inc, St Jude Medical, St. Paul, MN, USA). The analysis was performed in $1 \mathrm{~mm}$ longitudinal intervals within treated segments and $5 \mathrm{~mm}$ proximal and distal. Image quality was assessed using a four-point scale (excellent, good, moderate, non-diagnostic) and only excellent pullbacks, i.e., with $>95 \%$ of cross sections with full lumen contour visibility, were included in the final analysis. All BVS were investigated with regard to strut apposition, strut fracture, edge dissections, and thrombus formations. Every single strut was analyzed in each OCT frame. Struts were considered malapposed when the abluminal surface was separated from the vessel wall.

Three-dimensional reconstructions of OCT were performed for an optimal visualization of bifurcations. Ostia of all side branches of $>1.5 \mathrm{~mm}$ diameter were assessed visually and classified as follows: non-jailed SB, when no compartments were present in the SB orifice; jailed SB, when BVS struts separated the orifice of SB into compartments with different patterns $(\mathrm{V}, \mathrm{T}, \mathrm{H}$, and double $\mathrm{T})$ as described previously [17].

Edge dissection of $>30 \%$ of lumen circumference was considered as significant. Procedural strut fracture was defined if two struts overhung each other in the same angular sector of the lumen and/or if struts were located in the lumen without any connection with other struts [18].

The use of OCT was left at the discretion of the operator and was especially used in case of a large thrombus burden,

Table 1 Baseline characteristics

\begin{tabular}{ll}
\hline & Baseline characteristics $(n=106)$ \\
\hline Age & $61.0 \pm 10.7$ \\
Gender $($ male $)$ & $81(76.4)$ \\
BMI $\left(\mathrm{kg} / \mathrm{m}^{2}\right)$ & $27.5 \pm 3.5$ \\
Stable angina & $62(58.5)$ \\
ACS & $44(41.5)$ \\
STEMI & $18(17.0)$ \\
Cardiovascular history & \\
Prior Ml & $16(15.1)$ \\
Stroke & $4(3.8)$ \\
Cardiovascular risk factors & \\
Hypertension & $47(44.3)$ \\
Hyperlipidemia & $56(52.8)$ \\
DM & $21(19.8)$ \\
Smoking, current & $34(32.1)$ \\
Obesity & $22(20.8)$ \\
FH & $43(40.6)$ \\
Hemodynamics & \\
LVEF & $59.3 \pm 13.3$ \\
LVEDP & $17.9 \pm 7.3$ \\
HR & $71.5 \pm 15.5$ \\
SBP & $130.8 \pm 23.3$ \\
DBP & $70.7 \pm 10.6$ \\
Adjunctive therapy & \\
Thrombectomy & \\
GP & \\
\end{tabular}

Depicted are counts, $n$, incidence $(\%)$ or mean \pm SD

$A C S$ acute coronary syndrome, $B M I$ body mass index, $D B P$ diastolic blood pressure, $D M$ diabetes mellitus, $F H$ known family history, $G P$ glycoprotein 1lb/lla inhibitor, $H R$ heart rate, $L V E F$ left ventricle ejection fraction, $L V E D P$ left ventricle end-diastolic pressure, $M I$ myocardial infarction, SBP systolic blood pressure, STEMI ST-segment elevation myocardial infarction 

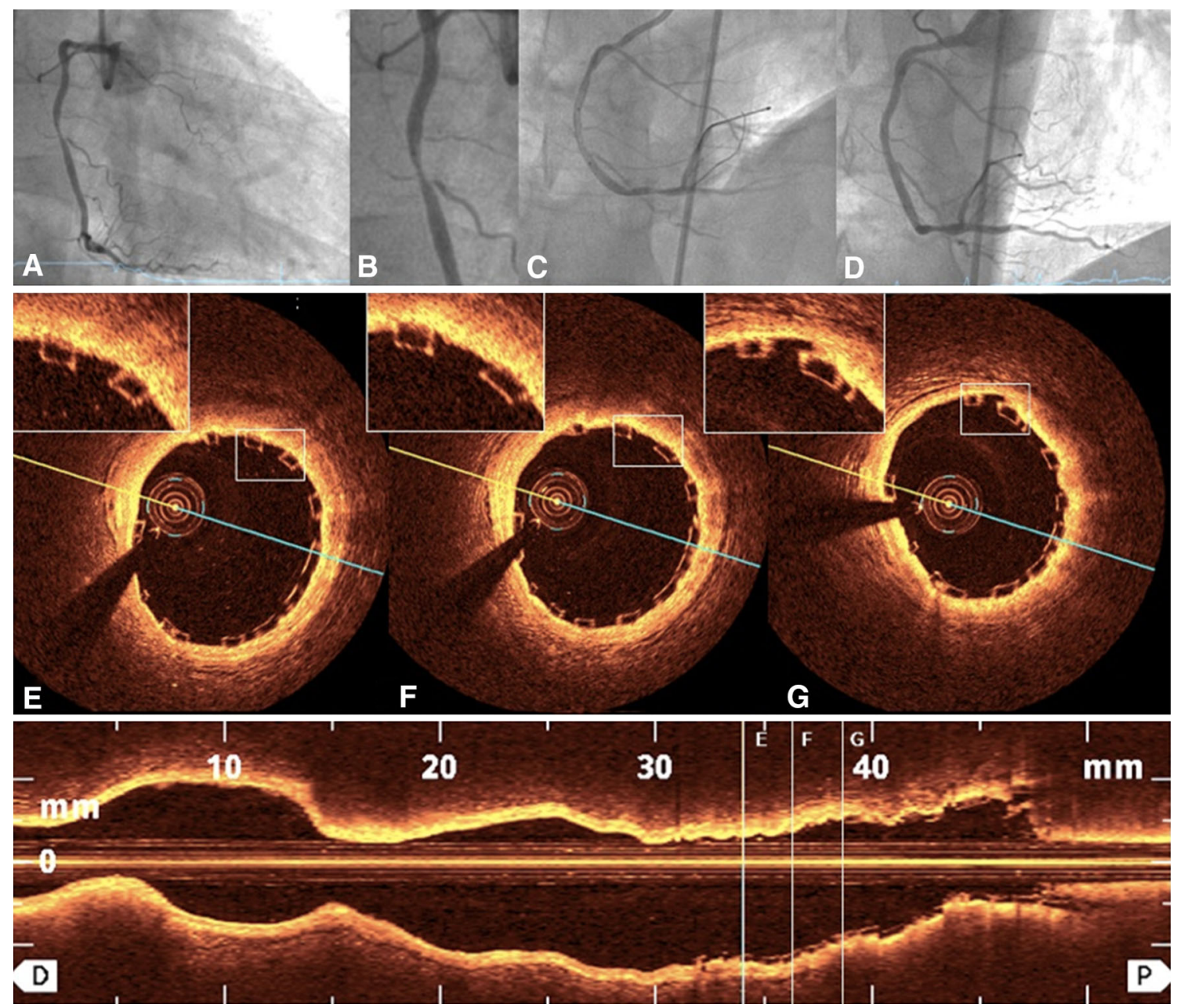

Fig. 2 BVS in type A lesion. Type A lesion in the middle portion of the right coronary artery (a and b) predilated with a $3.0 \times 15 \mathrm{~mm}$ balloon and subsequently covered by $3.5 \times 20 \mathrm{~mm}$ BVS (c) with

in STEMI patients, bifurcations, and to track the BVS implantation after CTO recanalization. We intended to avoid OCT evaluation in patients with hemodynamic deterioration and chronic renal failure. OCT evaluation was performed by the investigator blinded to the clinical characteristics and outcome.

\section{SYNTAX score}

SYNTAX score assessment was performed by a cardiologist blinded to the clinical characteristics and outcomes of the patients using a scoring system for all significant lesions ( $\geq 50 \%$ ) in the vessels $\geq 1.5 \mathrm{~mm}$ in diameter using the SYNTAX score algorithm. The SYNTAX score was calculated using angiography just after the first dilatation of the culprit vessel, thereby allowing inclusion of all significant lesions [19]. excellent angiographic result (d). The OCT pullback documented well-apposed struts in all cross sections $(\mathbf{e}-\mathbf{g})$

Outcomes

Follow-up analysis included device-related composite outcome measures of cardiac death, target vessel myocardial infarction, ischemia-driven TLR, and patient-related outcome measure of all-cause death. Any reinfarction and any revascularization was collected routinely by using standardized clinical questionnaire for hospital quality assessment. Furthermore, we evaluated the rate of ischemia-driven TLR and definite/possible/probable scaffold thrombosis.

\section{Statistics}

Data are presented as percentages mean \pm SD. Categorical variables were compared with Chi square test. A $p$ value $<0.05$ was considered to be statistical significant. 


\section{Results}

Clinical characteristics

Patients' baseline characteristics are presented in Table 1. The average age was $61.0 \pm 10.7$ years with only $35 \%$ patients $(n=37)$ being older than 65 years. PCI was successfully performed in all patients $(n=106)$. Full revascularization was obtained in $87 \%$ of patients $(n=92)$. Mean left ventricular ejection fraction was $59.3 \pm 13.3 \%$. Four percent of patients $(n=4)$ required GP IIb/IIIa infusion and in $13 \%(n=14)$ manual thrombectomy was performed. The study flowchart has been presented on Supplementary Fig. 1.

\section{BVS implantation and OCT}

In total, 193 BVS were implanted with an average amount of $1.82 \pm 1.19$ per patient and average length of $42.6 \pm 30.7 \mathrm{~mm}$ per patient. The minimal length of implanted BVS was $18 \mathrm{~mm}$ and the maximal length $186 \mathrm{~mm}$ (7 BVS in one patient). The scaffold diameters used were 2.5, 3.0 and $3.5 \mathrm{~mm}$. The mean SYNTAX score was $14.4 \pm 10.6$ (range 1-51). The implantation of BVS was extended to more acute situations with increasing experience of the operators (Fig. 1). Out of 139 lesions covered by BVS, $25 \%(n=34)$ were defined as type A (Fig. 2) and $34 \%(n=47)$ as type B1. $90 \%$ of patients $(n=95)$ had at least one of the following characteristics: $>65$ years $(35 \%)$, ACS $(42 \%)$, tortuous vessels $(13 \%)$, calcified $(17 \%)$ or thrombotic lesions (12\%), lesions defined by AHA type B2/C (42\%), bifurcations (16\%), CTO (9\%), or restenosis (14\%) (Table 2). Three patients with coronary dissection received BVS. The procedural success rate was $97 \%$. TIMI 3 flow grade was restored in all patients. Three BVS were not implanted due to the inability to pass the lesion. These patients were excluded from the final analysis. In two cases coronary artery rupture occurred and was successfully covered by stent graft implantation.

OCT was performed at the end of PCI in 36 of the 106 patients (34\%) in which BVS implantation was considered most challenging and high risk, i.e., after CTO recanalization (Fig. 3), in long left anterior descending artery dissection (Fig. 4), in-stent restenosis (Fig. 5) and bifurcations (Fig. 6) and in patients with thrombotic occlusion during an STEMI event (Fig. 7). Six pullbacks were excluded due to the suboptimal imaging quality. All OCT pullbacks and cross-sections showed an excellent result after BVS implantation, with no evidence of significant postprocedural edge dissection, huge thrombus load, incidence of scaffold dislodgement, or scaffold disruption.
Table 2 Angiography characteristics

\begin{tabular}{ll}
\hline & $\begin{array}{l}\text { Angioraphic characteristics } \\
(n=106)\end{array}$ \\
\hline Angiography & $44(41.5)$ \\
Single-vessel disease & $62(58.5)$ \\
Multivessel disease & $14.4 \pm 10.6$ \\
SYNTAX score & $92(86.8)$ \\
Full revascularization & $22(20.8)$ \\
TIMI flow 0 at baseline & $106(100)$ \\
TIMI flow 3 after PCI & 139 \\
Lesions treated by BVS & $34(24.5)$ \\
Type A & $47(33.8)$ \\
Type B1 & $34(24.5)$ \\
Type B2 & $24(17.2)$ \\
Type C & $1.82 \pm 1.19$ \\
BVS implanted per patient & $10(9.4)$ \\
Unrestricted indications & $15(14.2)$ \\
Chronic total occlusion & $17(16.0)$ \\
Restenosis & $18(17.0)$ \\
Bifurcations & $13(12.3)$ \\
Heavy calcifications & $14(13.2)$ \\
Thrombus & \\
Tortuous vessel & \\
\hline Depicted &
\end{tabular}

Depicted are counts, $n$ incidence $(\%)$ or mean \pm SD

TIMI thrombolysis in myocardial infarction

Out of 10,157 struts evaluated within 1,117 cross-sections from 30 remaining patients, 302 were classified as malapposed $(2.9 \%)$. Only in eight patients the rate of malapposed struts was $>5 \%$. Protruding residual thrombus formations after PCI were apparent significantly more often in patients referred for invasive treatment due to ACS compared with non-ACS patients (ACS vs. non-ACS patients: $47.5 \%$ cross-sections vs. $37.2 \%$ cross-sections, $p<0.001)$. Three-dimensional reconstruction of OCT pullbacks documented $45 \mathrm{SB}$ of diameter $>1.5 \mathrm{~mm}$ covered by the scaffold struts, out of which 41 were available for evaluation. The different patterns of compartmentalization were recorded as follows: $20 \%$ non-jailed SB $(n=8)$, $17 \%$ V-type jailed SB $(n=7), 39 \%$ T-type jailed SB $(n=16), 17 \%$ H-type jailed SB $(n=7)$, and $7 \%$ double T-type jailed SB $(n=3)$.

Follow-up

Complete follow-up was available in $92 \%$ patients $(n=98)$. The mean follow-up period was $147 \pm 119$ days. The rate of patient-related outcome (MACE) was $6.1 \%(n=6)$ and device-related outcome $2.0 \%(n=2)$ (Table 3$)$. 
Fig. 3 BVS in true chronic total occlusion. Elective recanalization of a chronic total occlusion of the right coronary artery (RCA) (a). After crossing the CTO with a pilot guidewire and an extensive vascular sealing with an Avion-Plus $1.25 \times 20 \mathrm{~mm}$ balloon, Maverick $2.0 \times 20 \mathrm{~mm}$ balloon and Maverick $2.5 \times 30 \mathrm{~mm}$ balloon (b, dissection-white arrow), two BVS $2.5 \times 28 \mathrm{~mm}$ were implanted in the distal and medial portion of the RCA. Subsequently, after catheter exchange (AL1-to-JR4-sideholes) and BMW guidewire placement, the predilatation of the proximal and ostial portion of the RCA was obtained with the use of a Maverick $3.0 \times 15 \mathrm{~mm}$ balloon. Finally, the third BVS $3.0 \times 18 \mathrm{~mm}$ was implanted to cover the ostial part of the RCA (c and $\mathbf{d})$. The OFDI demonstrated an optimal postprocedural result $(\mathbf{d}-\mathbf{l})$ with well-apposed scaffold struts $(\mathbf{e}-\mathbf{i})$ and full coverage of iatrogenic dissections after the recanalization. The thickness of two overlapping struts was $300 \mu \mathrm{m}$ (f and i, pullbackSupplemental video 1). The OFDI after 5-month follow-up demonstrated full coverage of BVS struts ( $\mathbf{j}-\mathbf{n}$, pullbackSupplemental video 2) and an optimal result in angiography $(\mathbf{o}-\mathbf{r})$

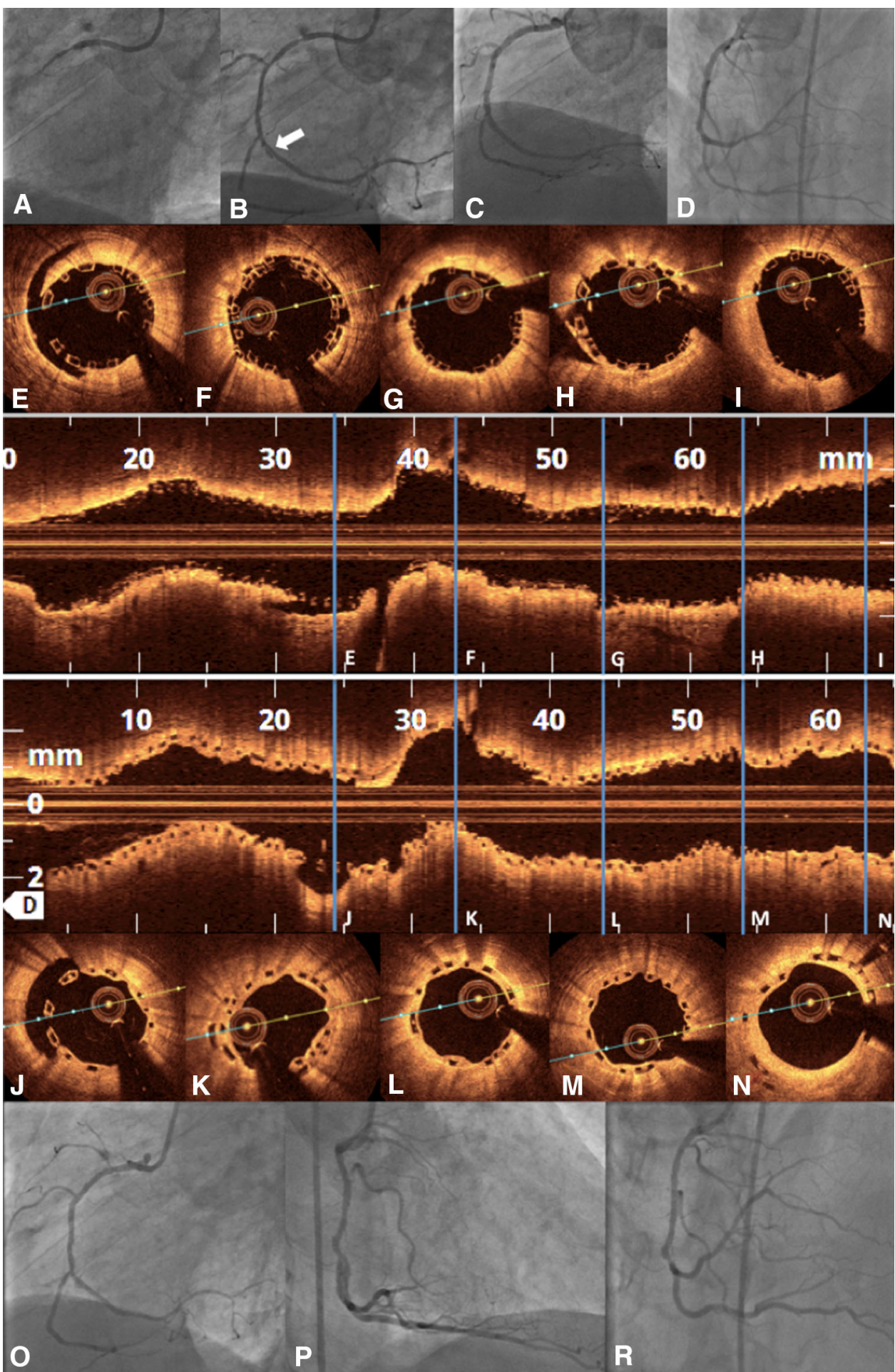

Two patients died, one of cardiovascular cause. One patient underwent urgent $\mathrm{CABG}$, while two patients had definite scaffold thrombosis (one acute and one subacute scaffold thrombosis). The acute scaffold thrombosis has been documented by OCT [20]. No possible/probable scaffold thrombosis was documented in this subset.

\section{Discussion}

Our preliminary experience with the use of second-generation everolimus-eluting BVS in a wide patient spectrum suggests that these novel scaffolds are feasible and efficacious even in unstable patients and complex lesions. 

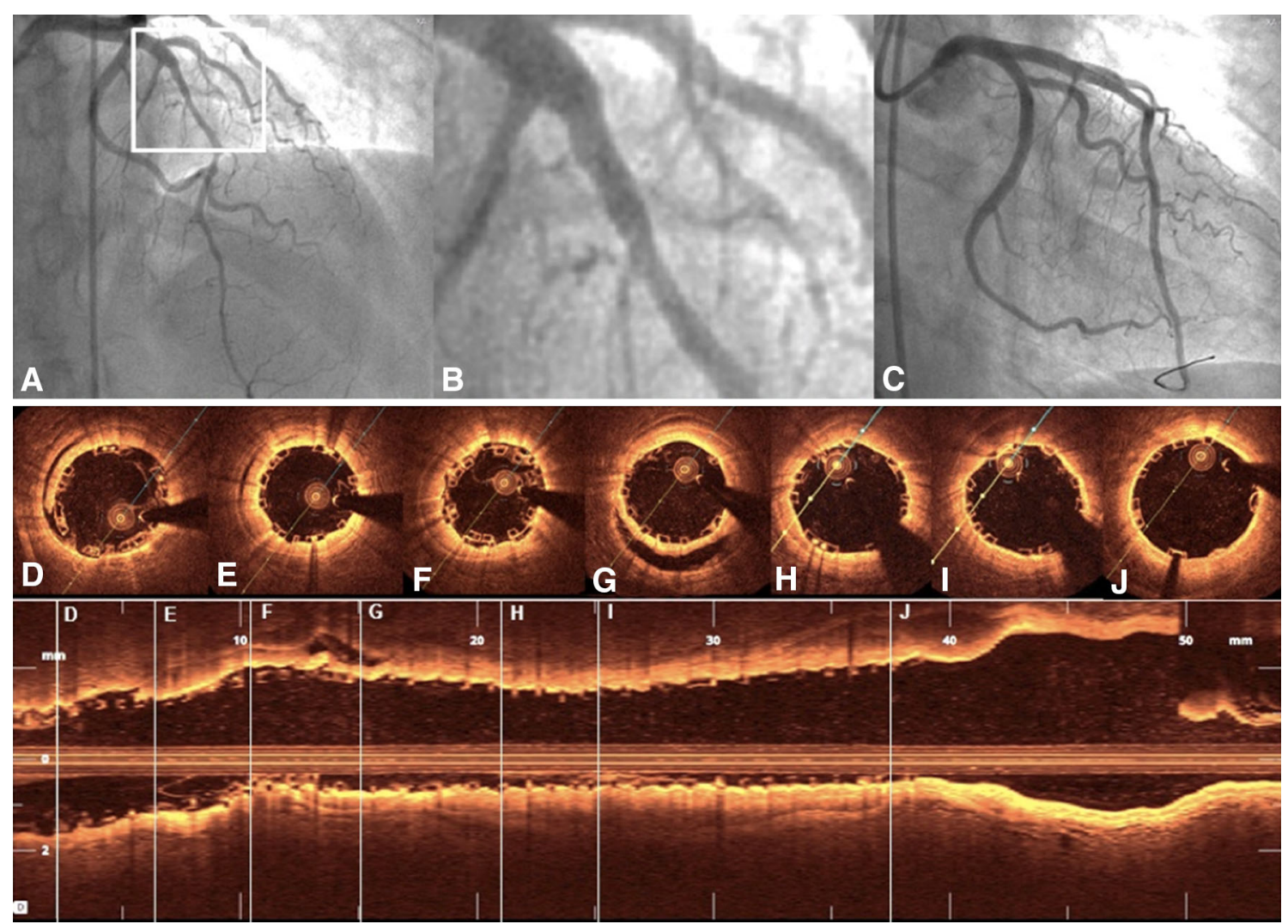

Fig. 4 BVS in a long dissection in young adult. Non-ST segment elevation myocardial infarction with long dissection starting in the middle portion of the left anterior descending artery (LAD) (a and b). After thrombectomy and extensive dilatation with a $2.5 \times 30 \mathrm{~mm}$ balloon, five BVS were implanted (three times $2.5 \times 28 \mathrm{~mm}$, $3.0 \times 28 \mathrm{~mm}$, and $3.5 \times 28 \mathrm{~mm})(\mathbf{c})$. The OCT documented a satisfactory result in the LAD $(\mathbf{d}-\mathbf{j})$; (pullback-Supplemental video 3)
Indeed, the unrestricted use of BVS at both institutions included also elderly patients, those with ACS and/or complex lesions including chronic total occlusions, massive calcifications, restenosis, and bifurcation lesions.

Currently, the most commonly used second-generation DES with advanced design features shows a substantial reduction in adverse outcomes when compared with firstgeneration paclitaxel- or sirolimus-eluting stents and in particular BMS. The permanent metal structure of current stents prevents the recoil process and negative remodeling. However, the metal alloy remains a source of inflammation predisposing to neoatherosclerosis and ST and prevents normal coronary vasomotion during episodes of increased demand $[21,22]$.

These remaining disadvantages of metal scaffolding prompted the exploration of better treatment strategies in patients with CAD. The potential advantage of bioabsorbable scaffolds is the fact that the foreign body only transiently remains present, allowing for proper healing and later normal coronary vasomotion. Furthermore, implantation of bypass grafts remains possible, if later on required. Indeed, the current lactic acid BVS resolves within 2-3 years [23]. Also, first experiences including a few patients with simple lesions were published using other scaffolds, i.e., absorbable metal scaffolds [24, 25]. In contrast to earlier bioabsorbable magnesium stents [24], the everolimus-eluting BVS retains important features of second-generation DES. The bioabsorption of the lactic acid scaffold may result in a reduction of chronic inflammation processes, thereby reducing vessel irritation and restoration of natural vascular function and positively influencing the blood velocity as well as endothelial shear stress [26].

Second-generation BVS has been designed to overcome limitations of metal stents including permanent double layers of struts, struts at the side branch ostium, and stent under deployment due to vasoconstriction or thrombus sequestration. However, data regarding the potential use of BVS in bifurcation lesions and in emergency cases are still scarce. No original data are available, i.e., to affirm the performance of BVS to pass the struts of a previously implanted scaffold in the main branch. In our work we present the feasibility of the BVS T-stenting technique regardless of its relatively high crossing profile. 


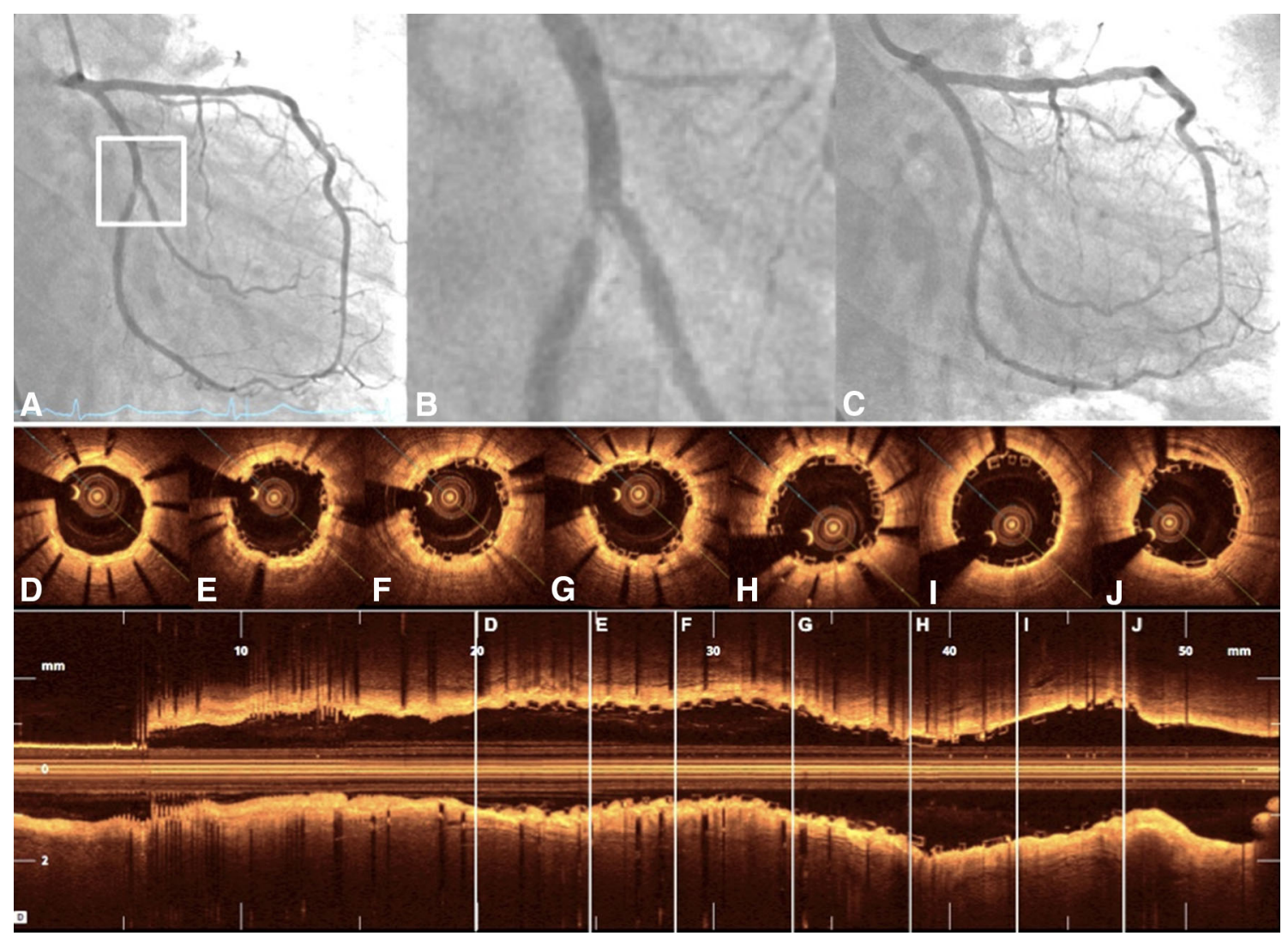

Fig. 5 BVS in in-stent-stenosis. BVS implantation in a stent restenosis of a bifurcation lesion after biolimus-eluting stent implantation in the middle portion of the circumflex artery (LCx) (a and b). After extensive predilatation in the marginal branch and LCx with $2.5 \times 15 \mathrm{~mm}$ and $2.5 \times 30 \mathrm{~mm}$ drug-eluting balloons, a

Furthermore, BVS may be an option in patients with stent restenosis requiring stent-in-stent implantation, contraindications to prolonged DAPT, and those with long lesions [27]. Although, the scaffold seems to be covered by endothelial cells early on after implantation, the requirement of prolonged DAPT after BVS implantation is still uncertain. In patients with in-stent restenosis, no-flow limiting dissections, and acceptable nonstent like primary result, the use of drug-coated balloons (DCB) is one of the possible therapy options. DCB could be also a considered in case of contraindications for prolonged DAPT. Unfortunately, POBA by itself has many limitations including, i.e., flow-limiting dissections. Moreover, DCB could not control the elastic recoil after PCI when no stent was implanted. Thus, BVS might be more efficient in thrombotic lesions, after plaque ruptures, in flow-limiting dissections, and especially in young patients.

Although currently not recommended, BVS may represent the treatment of choice also in patients with CTO, in which commonly the entire vessel is affected by the
$2.5 \times 28 \mathrm{~mm}$ BVS was implanted. Due to small edge dissection after BVS implantation, a second $3.0 \times 18 \mathrm{~mm}$ BVS was used to cover the proximal portion of the $\mathrm{LCx}(\mathbf{c})$. OCT pullback recorded an excellent postprocedural result $(\mathbf{d}-\mathbf{j})$; (pullback-Supplemental video 4)

atherosclerotic process. However, data regarding the safety and performance in a wide spectrum of population is still limited. Particularly, scaffold overlap has been hypothesized to be prone to the delayed healing process, due to a thickness of minimum $300 \mu \mathrm{m}$. In our representative case of CTO treated with BVS, full strut coverage was documented after 5 months of follow-up (Fig. 3) despite the strut malapposition rate of $7.1 \%$ within three scaffolds of a summarized length of $74 \mathrm{~mm}$.

Of note, in our real-world population, the MACE rate was comparable with that reported for the unrestricted use of second-generation DES [28]. The high rate of ST $(2.1 \%)$ observed in our population may be related to a suboptimal lesion preparation and/or malapposed scaffolds [20]. In patients with ST, the scaffold was indeed incorrectly implanted as documented by OCT. In our experience, ST occurred in an elderly patient referred for primary PCI due to ACS, where BVS was implanted in a heavily calcified LAD [20].

Currently, the applicability of BVS in calcified lesions is a matter of debate. Most physicians are still skeptical with 

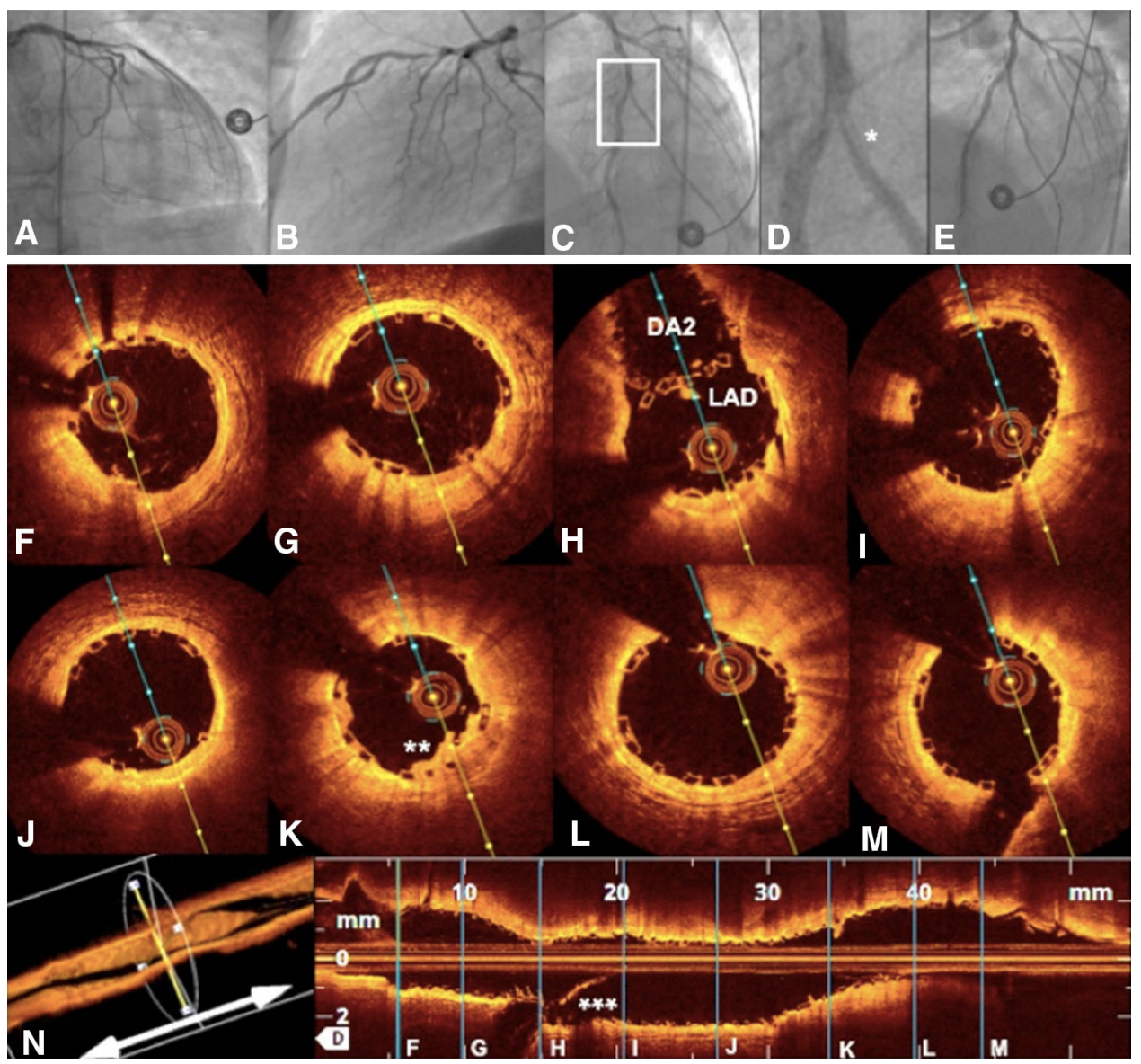

Fig. 6 BVS-T stenting of a bifurcation lesion. Bifurcation lesion in acute coronary syndrome and slow flow in left anterior descending artery (LAD, a and b). After passing the lesion with a BMW guidewire, manual thrombectomy, and vascular sealing with a Maverick $2.5 \times 15 \mathrm{~mm}$ balloon, a BVS $3.0 \times 18 \mathrm{~mm}$ was implanted in the middle portion of the LAD and extended by a second BVS $3.0 \times 12 \mathrm{~mm}$. The second BMW guidewire was retrieved to the bifurcation of the second diagonal branch (DA2) and advanced again through the struts of the previously implanted BVS. After subsequent

regard to the device deliverability and radial strength [29]. Indeed, unlike the currently used DES, the deliverability of BVS seems more challenging due to the strut thickness of $150 \mu \mathrm{m}$ and crossing profile of $1.4 \mathrm{~mm}$ [30]. However, the new BVS (ABSORB 1.1) currently on the market has several modifications as compared to the previous one (ABSORB 1.0) investigated in cohort A. Also, the polymer underwent several modifications related to the polymer processing, improved device retention, and scaffold design to give more prolonged radial support [31]. Stents should be designed to withstand the difference between the transluminal and intraluminal pressures up to $175 \mathrm{mmHg}$. Thus, concerning the safety issues, the minimal acceptable collapse pressure for stents is $300 \mathrm{mmHg}[32,33]$. Furthermore, the lumen of the vessel appears to stabilize approximately 3 months after PCI [34]. dilatation in the ostial portion of the DA2 with a Maverick $2.5 \times 15 \mathrm{~mm}$ balloon, a BVS $2.5 \times 12 \mathrm{~mm}$ was gently positioned through the BVS struts to seal the iatrogenic dissection (c and d). The final angiogram (e) and optical coherence tomography (OCT) (fn) demonstrated an optimal postprocedural result with well-apposed struts in all cross sections (e-m); (pullback-Supplemental video 5). *Dissection in DA2; **protruding thrombi inapparent in angiography; ***BMW guidewire to DA2

Another downside of current BVS is the fact that they are radiolucent, except for platinum markers. Thus, in cases with long and/or calcified lesions, accurate lesion preparation including the use of noncompliant balloons appears advisable. Furthermore, subsequent intravascular imaging should be obtained to avoid incomplete scaffold apposition. Potential malapposition can be immediately sealed by accurate balloon post dilatation. Post dilatation, however, should be performed with caution, since overexpansion may fracture struts and disrupt BVS [35]. Despite the wide patient spectrum in this study, the result with regard to strut malapposition was comparable with the OCT substudy of cohort B, where no complex patients were enrolled $(p=0.13)[36]$.

The main limitation of the study was its observational nature, based on the double-center cohort. We did not 

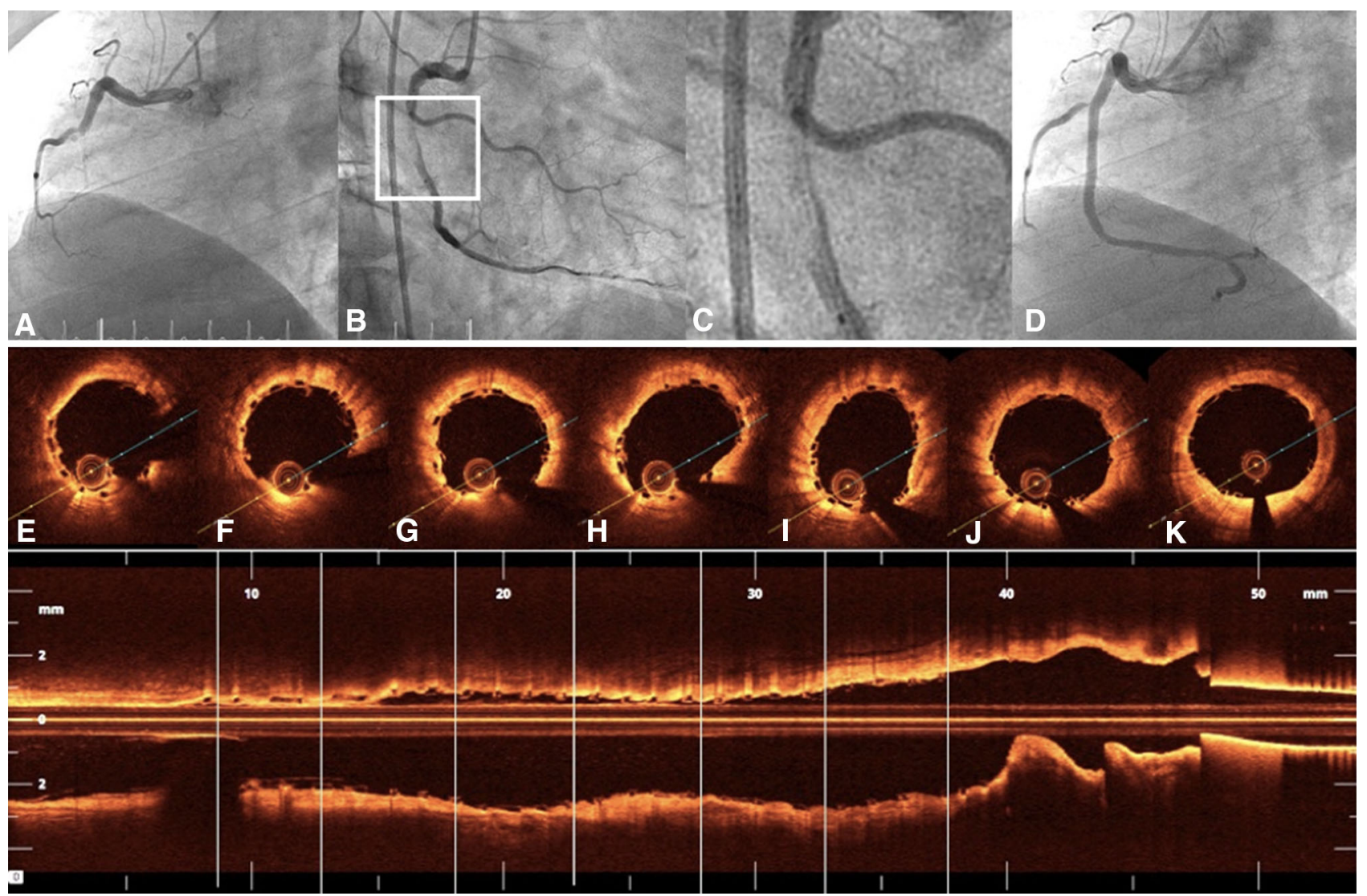

Fig. 7 BVS in acute ST-segment elevation myocardial infarction. Right coronary artery occluded with a thrombus during the acute course of an inferior ST-segment elevation myocardial infarction (a). After manual thrombectomy with an Export catheter and extensive

Table 3 Outcomes

\begin{tabular}{ll}
\hline Total no. of patients & Outcomes $(n=98)$ \\
\hline Device-related end point & $2(2.0)$ \\
Cardiac death & $1(1.0)$ \\
Target vessel Ml & $2(2.0)$ \\
TLR & $2(2.0)$ \\
Patient-related end point & $6(6.1)$ \\
All-cause death & $2(2.0)$ \\
Any reinfarction & $3(3.1)$ \\
Any revascularization & $4(4.1)$
\end{tabular}

Depicted are counts, $n$, incidence $(\%)$

include a control group and the follow-up period differed between patients. The follow-up was not prespecified and no minimal observation time period was required. DES were additionally implanted in 26 patients, which could have impact on outcome. The implantation of DES was left to the operator's discretion. predilatation with a $3.0 \times 15 \mathrm{~mm}$ balloon, a $3.5 \times 28 \mathrm{~mm}$ BVS was implanted (b and $\mathbf{c}$, BVS positioning). Final angiography cine (d) and OCT pullback documented an excellent result $(\mathbf{e}-\mathbf{k})$. *Residual adherent thrombi (pullback-Supplemental video 6)

\section{Conclusions}

In summary, our study demonstrates the feasibility and good performance of BVS in an unselected population including patients with ACS and complex coronary anatomy. The use of BVS may be feasible in patients at high risk of restenosis, particularly after extensive stent implantation of target vessel and with a history of diabetes mellitus. Nonetheless, in high-risk patients, i.e., referred for primary PCI due to STEMI and thrombotic lesion including left main and ostial LAD, we suggest an adequate lesion preparation and the use of intravascular imaging to prevent malapposition and device-related adverse events.

Acknowledgments $\mathrm{MJ}$ is a recipient of an unrestricted grant for training fellowship from the European Association of Percutaneous Cardiovascular Interventions.

Conflict of interest CT has received honoraria from Abbott Vascular, Baar, Switzerland. The University Heart Center, Zurich has 
received unrestricted educational grants from Abbott Vascular, Switzerland.

Open Access This article is distributed under the terms of the Creative Commons Attribution License which permits any use, distribution, and reproduction in any medium, provided the original author(s) and the source are credited.

\section{References}

1. Gruntzig A (1978) Transluminal dilatation of coronary-artery stenosis. Lancet 1:263

2. Serruys PW, de Jaegere P, Kiemeneij F, Macaya C, Rutsch W, Heyndrickx G, Emanuelsson H, Marco J, Legrand V, Materne P et al (1994) A comparison of balloon-expandable-stent implantation with balloon angioplasty in patients with coronary artery disease. Benestent Study Group. N Engl J Med 331:489-495

3. Eisenstein EL, Anstrom KJ, Kong DF, Shaw LK, Tuttle RH, Mark DB, Kramer JM, Harrington RA, Matchar DB, Kandzari DE, Peterson ED, Schulman KA, Califf RM (2007) Clopidogrel use and long-term clinical outcomes after drug-eluting stent implantation. JAMA 297:159-168

4. Stefanini GG, Holmes DR Jr (2013) Drug-eluting coronary-artery stents. N Engl J Med 368:254-265

5. Gomez-Lara J, Brugaletta S, Farooq V, Onuma Y, Diletti R, Windecker S, Thuesen L, McClean D, Koolen J, Whitbourn R, Dudek D, Smits PC, Chevalier B, Regar E, Veldhof S, Rapoza R, Ormiston JA, Garcia-Garcia HM, Serruys PW (2011) Head-tohead comparison of the neointimal response between metallic and bioresorbable everolimus-eluting scaffolds using optical coherence tomography. JACC Cardiovasc Interv 4:1271-1280

6. Diletti R, Farooq V, Girasis C, Bourantas C, Onuma Y, Heo JH, Gogas BD, van Geuns RJ, Regar E, de Bruyne B, Dudek D, Thuesen L, Chevalier B, McClean D, Windecker S, Whitbourn RJ, Smits P, Koolen J, Meredith I, Li X, Miquel-Hebert K, Veldhof S, Garcia-Garcia HM, Ormiston JA, Serruys PW (2013) Clinical and intravascular imaging outcomes at 1 and 2 years after implantation of absorb everolimus eluting bioresorbable vascular scaffolds in small vessels. Late lumen enlargement: does bioresorption matter with small vessel size? Insight from the ABSORB cohort B trial. Heart 99:98-105

7. Ormiston JA, Serruys PW, Regar E, Dudek D, Thuesen L, Webster MW, Onuma Y, Garcia-Garcia HM, McGreevy R, Veldhof S (2008) A bioabsorbable everolimus-eluting coronary stent system for patients with single de-novo coronary artery lesions (ABSORB): a prospective open-label trial. Lancet 371:899-907

8. Dudek D, Onuma Y, Ormiston JA, Thuesen L, Miquel-Hebert K, Serruys PW (2012) Four-year clinical follow-up of the ABSORB everolimus-eluting bioresorbable vascular scaffold in patients with de novo coronary artery disease: the ABSORB trial. EuroIntervention 7:1060-1061

9. Kocka V, Maly M, Tousek P, Budesinsky T, Lisa L, Prodanov P, Jarkovsky J, Widimsky P (2014) Bioresorbable vascular scaffolds in acute ST-segment elevation myocardial infarction: a prospective multicentre study 'Prague 19'. Eur Heart J 35:787-794

10. Gori T, Schulz E, Hink U, Wenzel P, Post F, Jabs A, Munzel T (2014) Early outcome after implantation of absorb bioresorbable drug-eluting scaffolds in patients with acute coronary syndromes. EuroIntervention 9:1036-1041

11. Diletti R, Serruys PW, Farooq V, Sudhir K, Dorange C, MiquelHebert K, Veldhof S, Rapoza R, Onuma Y, Garcia-Garcia HM, Chevalier B (2012) ABSORB II randomized controlled trial: a clinical evaluation to compare the safety, efficacy, and performance of the absorb everolimus-eluting bioresorbable vascular scaffold system against the XIENCE everolimus-eluting coronary stent system in the treatment of subjects with ischemic heart disease caused by de novo native coronary artery lesions: rationale and study design. Am Heart J 164:654-663

12. Muramatsu T, Onuma Y, Garcia-Garcia HM, Farooq V, Bourantas CV, Morel MA, Li X, Veldhof S, Bartorelli A, Whitbourn R, Abizaid A, Serruys PW (2013) Incidence and short-term clinical outcomes of small side branch occlusion after implantation of an everolimus-eluting bioresorbable vascular scaffold: an interim report of 435 patients in the absorb-extend single-arm trial in comparison with an everolimus-eluting metallic stent in the spirit first and II trials. JACC Cardiovasc Interv 6:247-257

13. Wiebe J, Mollmann H, Most A, Dorr O, Weipert K, Rixe J, Liebetrau C, Elsasser A, Achenbach S, Hamm C, Nef H (2014) Short-term outcome of patients with ST-segment elevation myocardial infarction (STEMI) treated with an everolimus-eluting bioresorbable vascular scaffold. Clin Res Cardiol 103: $141-148$

14. Thygesen K, Alpert JS, Jaffe AS, Simoons ML, Chaitman BR, White HD, Katus HA, Apple FS, Lindahl B, Morrow DA, Chaitman BA, Clemmensen PM, Johanson P, Hod H, Underwood R, Bax JJ, Bonow RO, Pinto F, Gibbons RJ, Fox KA, Atar D, Newby LK, Galvani M, Hamm CW, Uretsky BF, Steg PG, Wijns W, Bassand JP, Menasche P, Ravkilde J, Ohman EM, Antman EM, Wallentin LC, Armstrong PW, Januzzi JL, Nieminen MS, Gheorghiade M, Filippatos G, Luepker RV, Fortmann SP, Rosamond WD, Levy D, Wood D, Smith SC, Hu D, Lopez-Sendon JL, Robertson RM, Weaver D, Tendera M, Bove AA, Parkhomenko AN, Vasilieva EJ, Mendis S (2012) Third universal definition of myocardial infarction. Eur Heart J 33:2551-2567

15. Wright RS, Anderson JL, Adams CD, Bridges CR, Casey DE Jr, Ettinger SM, Fesmire FM, Ganiats TG, Jneid H, Lincoff AM, Peterson ED, Philippides GJ, Theroux P, Wenger NK, Zidar JP, Antman EM, Califf RM, Chavey WE 2nd, Hochman JS, Levin TN (2011) 2011 ACCF/AHA focused update incorporated into the ACC/AHA 2007 guidelines for the management of patients with unstable angina/non-ST-elevation myocardial infarction: a report of the American College of Cardiology Foundation/ American Heart Association Task Force on practice guidelines developed in collaboration with the American Academy of Family Physicians, Society for Cardiovascular Angiography and Interventions, and the Society of Thoracic Surgeons. J Am Coll Cardiol 57:e215-e367

16. Di Mario C, Werner GS, Sianos G, Galassi AR, Buttner J, Dudek D, Chevalier B, Lefevre T, Schofer J, Koolen J, Sievert H, Reimers B, Fajadet J, Colombo A, Gershlick A, Serruys PW, Reifart N (2007) European perspective in the recanalisation of chronic total occlusions (CTO): consensus document from the EuroCTO Club. EuroIntervention 3:30-43

17. Okamura T, Onuma Y, Garcia-Garcia HM, Regar E, Wykrzykowska JJ, Koolen J, Thuesen L, Windecker S, Whitbourn R, McClean DR, Ormiston JA, Serruys PW, Investigators ACB (2010) 3-Dimensional optical coherence tomography assessment of jailed side branches by bioresorbable vascular scaffolds: a proposal for classification. JACC Cardiovasc Interv 3:836-844

18. Serruys PW, Onuma Y, Ormiston JA, de Bruyne B, Regar E, Dudek D, Thuesen L, Smits PC, Chevalier B, McClean D, Koolen J, Windecker S, Whitbourn R, Meredith I, Dorange C, Veldhof S, Miquel-Hebert K, Rapoza R, Garcia-Garcia HM (2010) Evaluation of the second generation of a bioresorbable everolimus drug-eluting vascular scaffold for treatment of de novo coronary artery stenosis: six-month clinical and imaging outcomes. Circulation 122:2301-2312

19. Garg S, Sarno G, Serruys PW, Rodriguez AE, Bolognese L, Anselmi M, De Cesare N, Colangelo S, Moreno R, Gambetti S, 
Monti M, Bristot L, Bressers M, Garcia-Garcia HM, Parrinello G, Campo G, Valgimigli M (2011) Prediction of 1-year clinical outcomes using the SYNTAX score in patients with acute STsegment elevation myocardial infarction undergoing primary percutaneous coronary intervention: a substudy of the STRATEGY (Single High-Dose Bolus Tirofiban and Sirolimus-Eluting Stent Versus Abciximab and Bare-Metal Stent in Acute Myocardial Infarction) and MULTISTRATEGY (Multicenter Evaluation of Single High-Dose Bolus Tirofiban Versus Abciximab With Sirolimus-Eluting Stent or Bare-Metal Stent in Acute Myocardial Infarction Study) trials. JACC Cardiovasc Interv 4:66-75

20. Jaguszewski M, Wyss C, Alibegovic J, Luscher TF, Templin C (2013) Acute thrombosis of bioabsorbable scaffold in a patient with acute coronary syndrome. Eur Heart J 34:2046

21. Nakazawa G, Otsuka F, Nakano M, Vorpahl M, Yazdani SK, Ladich E, Kolodgie FD, Finn AV, Virmani R (2011) The pathology of neoatherosclerosis in human coronary implants bare-metal and drug-eluting stents. J Am Coll Cardiol 57: $1314-1322$

22. Virmani R, Guagliumi G, Farb A, Musumeci G, Grieco N, Motta T, Mihalcsik L, Tespili M, Valsecchi O, Kolodgie FD (2004) Localized hypersensitivity and late coronary thrombosis secondary to a sirolimus-eluting stent: should we be cautious? Circulation 109:701-705

23. Ormiston JA, Webster MW, Armstrong G (2007) First-in-human implantation of a fully bioabsorbable drug-eluting stent: the BVS poly-L-lactic acid everolimus-eluting coronary stent. Catheter Cardiovasc Interv 69:128-131

24. Erbel R, Di Mario C, Bartunek J, Bonnier J, de Bruyne B, Eberli FR, Erne P, Haude M, Heublein B, Horrigan M, Ilsley C, Bose D, Koolen J, Luscher TF, Weissman N, Waksman R, Investigators P-A (2007) Temporary scaffolding of coronary arteries with bioabsorbable magnesium stents: a prospective, non-randomised multicentre trial. Lancet 369:1869-1875

25. Haude M, Erbel R, Erne P, Verheye S, Degen H, Bose D, Vermeersch P, Wijnbergen I, Weissman N, Prati F, Waksman R, Koolen J (2013) Safety and performance of the drug-eluting absorbable metal scaffold (DREAMS) in patients with de-novo coronary lesions: 12 month results of the prospective, multicentre, first-in-man BIOSOLVE-I trial. Lancet 381:836-844

26. Serruys PW, Ormiston JA, Onuma Y, Regar E, Gonzalo N, Garcia-Garcia HM, Nieman K, Bruining N, Dorange C, MiquelHebert K, Veldhof S, Webster M, Thuesen L, Dudek D (2009) A bioabsorbable everolimus-eluting coronary stent system
(ABSORB): 2-year outcomes and results from multiple imaging methods. Lancet 373:897-910

27. Erne P, Schier M, Resink TJ (2006) The road to bioabsorbable stents: reaching clinical reality? Cardiovasc Intervent Radiol 29: $11-16$

28. Silber S, Windecker S, Vranckx P, Serruys PW (2011) Unrestricted randomised use of two new generation drug-eluting coronary stents: 2-year patient-related versus stent-related outcomes from the resolute all comers trial. Lancet 377:1241-1247

29. Tanimoto S, Serruys PW, Thuesen L, Dudek D, de Bruyne B, Chevalier B, Ormiston JA (2007) Comparison of in vivo acute stent recoil between the bioabsorbable everolimus-eluting coronary stent and the everolimus-eluting cobalt chromium coronary stent: insights from the absorb and spirit trials. Catheter Cardiovasc Interv 70:515-523

30. Ormiston JA, Serruys PW (2009) Bioabsorbable coronary stents. Circ Cardiovasc Interv. 2:255-260

31. Gogas BD, Farooq V, Onuma Y, Serruys PW (2012) The ABSORB bioresorbable vascular scaffold: an evolution or revolution in interventional cardiology? Hellenic J Cardiol 53: 301-309

32. Dobrin PB (1973) Influence of initial length on length-tension relationship of vascular smooth muscle. Am J Physiol 225: 664-670

33. Agrawal CM, Haas KF, Leopold DA, Clark HG (1992) Evaluation of poly(L-lactic acid) as a material for intravascular polymeric stents. Biomaterials 13:176-182

34. Serruys PW, Luijten HE, Beatt KJ, Geuskens R, de Feyter PJ, van den Brand M, Reiber JH, ten Katen HJ, van Es GA, Hugenholtz PG (1988) Incidence of restenosis after successful coronary angioplasty: a time-related phenomenon. A quantitative angiographic study in 342 consecutive patients at 1, 2, 3, and 4 months. Circulation 77:361-371

35. Ormiston JA, De Vroey F, Serruys PW, Webster MW (2011) Bioresorbable polymeric vascular scaffolds: a cautionary tale. Circ Cardiovasc Interv. 4:535-538

36. Gomez-Lara J, Radu M, Brugaletta S, Farooq V, Diletti R, Onuma Y, Windecker S, Thuesen L, McClean D, Koolen J, Whitbourn R, Dudek D, Smits PC, Regar E, Veldhof S, Rapoza R, Ormiston JA, Garcia-Garcia HM, Serruys PW (2011) Serial analysis of the malapposed and uncovered struts of the new generation of everolimus-eluting bioresorbable scaffold with optical coherence tomography. JACC Cardiovasc Interv 4:992-1001 